\title{
Perioperative Complications of Congenital Diaphragmatic Hernia Repair
}

\author{
Catarina Barroso $^{1,2}$ Jorge Correia-Pinto ${ }^{1,2}$ \\ ${ }^{1}$ Department of Pediatric Surgery, Hospital de Braga, Braga, Portugal \\ ${ }^{2}$ School of Medicine, University of Minho, Braga, Portugal \\ Address for correspondence Catarina Barroso, MD, Department of \\ Pediatric Surgery, Hospital de Braga, Sete Fontes, Braga 4710-243, \\ Portugal (e-mail: catabarroso@gmail.com).
}

Eur J Pediatr Surg

\begin{abstract}
Although improvements have been made, the management of congenital diaphragmatic hernia $(\mathrm{CDH})$ remains a major challenge for perinatologists and neonatal surgeons. Many aspects of the disease remain unknown and, being a rare entity, evidence-based data are hard to find. Surgical morbidity is considerable and affects long-term quality of life. Perioperative complications have been reviewed focusing on thoracoscopic repair. Intraoperative acidosis was more severe during thoracoscopy when compared with open surgery (OS), though it is possible that later neurodevelopment was not affected. Even so, strategies have been outlined to reduce acidosis, such as decreasing carbon dioxide $\left(\mathrm{CO}_{2}\right)$ insufflation after reduction of the herniated viscera into the abdomen is complete. The risk of pleural complications decreased after introduction of gentle ventilation techniques and minimally invasive surgery (MIS); thus, the use of a prophylactic intraoperative thoracic tube is not routinely required. Recurrence rate was higher in large CDH and following MIS repair. Technical demands

Keywords

- congenital diaphragmatic hernia

- perioperative complications

- thoracoscopic repair

- minimally invasive surgery play an important role, therefore, in avoiding complications; every step of the OS technique must be strictly accomplished. In large defects, the use of prosthetic patch might reduce recurrence rate, even by MIS repair, once again only if technical demands are overcome with meticulous rules of suturing. Thoracoscopy significantly reduced the incidence of bowel obstruction and recovery time and improved cosmesis. The best approach of $\mathrm{CDH}$ is yet to be found, and it goes far beyond the management of perioperative complications. Meanwhile randomized controlled studies, namely on the outcome of thoracoscopic repair, are required to inform further practice.
\end{abstract}

\section{Introduction}

Congenital diaphragmatic hernia $(\mathrm{CDH})$ remains a challenging surgical condition in neonatal period, which is frequently life threatening. Prevalence of CDH in Europe is 2.3 per 10,000 births while proportion of cases surviving to 1 week is around $70 \%$. A small increase in the prevalence over time has been noted. ${ }^{1}$ Prognosis is believed to be determined by the degree of pulmonary hypoplasia and hypertension and abnormal morphology of pulmonary vasculature. ${ }^{2-4}$

received

January 14, 2018

accepted

January 16, 2018
Given the great advances in neonatal intensive care and surgical techniques, one should expect an outcome improvement in the management of $\mathrm{CDH}$. However, the exponential progress along the years was not proportionally reflected on the clinical evolution of the children diagnosed with $\mathrm{CDH}$. Nowadays, the pathophysiology of lung insufficiency and persistent pulmonary hypertension are better understood, and survival rate has improved, but results remain disappointing: reported mortality rate is still high, and morbidity remains significant with chronic oxygen dependence,

(c) Georg Thieme Verlag KG Stuttgart · New York
DOI https://doi.org/ 10.1055/s-0038-1632374. ISSN 0939-7248. 
gastroesophageal reflux, poor growth and developmental delay, and prolonged postoperative hospitalization. The rarity of the disease makes it difficult to develop evidence-based protocols. $^{4,5}$

\section{Surgical Repair-Historical Aspects}

Bochdalek was the first to predict that children with $\mathrm{CDH}$ would benefit from surgical correction. In 1902, Heidenham performed the first successful operation in an infant, as later demonstrated by a favorable 18 -year-follow-up. ${ }^{6}$ It was only in 1940 that surgery became an accepted treatment for CDH when Ladd and Gross reported 9 out of 16 survivals after operation. After this, in 1946, Gross reported the first successful repair in a neonate $<24$ hours old, and early repair became the basis of treatment. Many changes have occurred since then. $\mathrm{CDH}$ which was previously a surgical emergency, now requires preoperative stabilization for outcomes improvement. $^{7}$ While open surgery (OS; thoracotomy or, mostly, laparotomy) has been traditionally performed for patients with $\mathrm{CDH}$, minimally invasive surgery (MIS; laparoscopy or thoracoscopy) emerged as a safe and feasible alternative. In 1995, Silen et al performed the first thoracoscopic approach of a CDH in an adolescent. ${ }^{8}$ Also, van der Zee and Bax reported a laparoscopy in a 6-month-old patient. ${ }^{9}$ Becmeur et al published a few years later a series of three patients with late presentation successfully treated by thoracoscopy. ${ }^{10}$ Each technique has advantages and disadvantages. MIS gradually gained popularity in the beliefs of a reduced duration of postoperative ventilation, less pain and use of short-term narcotics, faster recovery, shorter hospitalization, and less morbidity, such as chest wall deformities and small bowel obstruction. ${ }^{11-26}$ Even a sporadic debate still occurs about the best MIS approach for CDH (abdomen vs. thorax); thoracoscopy is preferred for most surgeons. ${ }^{15,22,27-30}$ It allows wider working space after reduction of herniated viscera, easier reduction mediated by pneumothorax, intermittent carbon dioxide $\left(\mathrm{CO}_{2}\right)$ insufflation, and better thoracic visualization. On the other hand, it hampers proper inspection for malrotation or other associated malformations. By laparoscopy, a third working trocar is often needed to open the diaphragmatic defect while safely pulling the viscera to the abdomen and, after reduction of abdominal contents, the working space is reduced requiring sustained insufflation. ${ }^{30}$

\section{Perioperative Complications and Evidence- based Treatment}

As previously mentioned, there are several approaches to repair $\mathrm{CDH}$ : by open technique through thoracotomy or laparotomy and by minimally invasive technique through thoracoscopy or laparoscopy. None of them was proven to be absolutely superior to another when it comes to perioperative complications. Instead, we can avoid certain complications by choosing one technique while increasing the risk for others. At our department, whenever is possible, thoracoscopy is performed to repair $\mathrm{CDH}$. We hereby reviewed the most common perioperative complications, highlighting the outcomes obtained in MIS. Also, although there is a lack of knowledge on what is the optimal care for $\mathrm{CDH}$, we tried to provide an overview through the evidence-based treatment of these complications.

\section{Intra-operative Complications}

Surgical morbidity tends to relate to the defect size, need for patch repair, and liver herniation. ${ }^{31,32}$

\section{Technical Difficulties}

In MIS, technical difficulties lead to conversion in approximately 3.4 to $75 \%$ of the cases, which were usually extensive diaphragmatic defects or difficulties reducing the liver and deterioration of clinical status, such as prolonged respiratory acidosis or hemodynamic instability. ${ }^{33}$ Whether starting with thoracoscopy and converting is disadvantageous (regarding hypercapnia, acidosis, and reduced cerebral oxygenation) is still unclear, but risks seem negligible when surgeons convert immediately after identifying a large defect. $^{34,35}$

\section{Bleeding and Damage of the Tissue}

To avoid intraoperative complications, the authors recommend that every step of the OS should be performed in thoracoscopy with extreme caution not to damage the tissue: first the reduction of small bowel, followed by the colon, and finally the spleen (for left-sided $\mathrm{CDH}$, which represents most of the authors' experience). Therefore, while holding the viscera, blunt forceps should be used, which should not be closed completely to avoid harming the tissue. To prevent bleeding, the pushing down traction of the stomach proved to be very helpful to aid positioning the spleen in the abdominal cavity. ${ }^{30}$

\section{Increased Abdominal Pressure}

In severe cases, namely in right-sided $\mathrm{CDH}$, the reduction of herniated viscera followed by the closure of the hernia defect and abdominal wall (if it is a laparotomy repair) might considerably increase abdominal pressure, leading to diaphragmatic compliance compromise, respiratory dysfunction, or even abdominal compartment syndrome. Although abdominal compartment syndrome was rare after $\mathrm{CDH}$ repair $(<1 \%)$, by laparotomy repair, delayed abdominal fascial closure was often required ( $>10 \%$ ), which was associated with increased morbidity (increased length of stay, fasting days, and duration of mechanical ventilation). ${ }^{36}$ In thoracoscopic repair, there are no reports of abdominal compartment syndrome, presumably because while reducing the herniated viscera there is no available space for viscera accommodation as it happens in OS (extracorporeally); in the presence of a large defect or tension after reducing the viscera, it is the standard care nowadays to use a prosthetic patch, thus preventing a compartment syndrome. ${ }^{37}$ Prosthetic patches have been used in 37 to $51 \%$ of $\mathrm{CDH}$ cases. ${ }^{27,38}$ Though previously suggested that the use of patch repair should be a relative contraindication for thoracoscopic repair, ${ }^{18,19,22,39}$ it proved to be feasible ${ }^{40}$ bringing a whole new debate in the approach of CDH. Hiradfar et al in 2016 reported a case of thoracoscopic repair in a 4-month- 
old boy who had not enough abdominal space to accommodate herniated viscera. They performed a wide transverse abdominal fasciotomy via laparoscopy inducing an iatrogenic ventral hernia; distended the abdomen by inducing pneumoperitoneum; and two days later, completed the thoracoscopic CDH repair using a prosthetic patch. ${ }^{41}$ As so, a transverse abdominal fasciotomy might be an alternative in MIS repair of CDH in an undeveloped abdomen.

\section{Acidosis}

Intraoperative hypercapnia and acidosis occur regardless of the approach used for $\mathrm{CDH}$ repair although it seems to be more severe during thoracoscopy. It is mostly explained for the respiratory compromise during surgery, lung collapse to allow adequate working space and also $\mathrm{CO}_{2}$ absorption from the induced pneumothorax. ${ }^{42}$ Some studies did not favor thoracoscopic approach, but most of them did not provide enough evidence supporting the idea. The only randomized controlled trial comparing MIS versus OS conducted so far showed that thoracoscopic repair is associated with severe intraoperative hypercapnia and acidosis, but its conclusions were based on the results of 10 operated patients ( 5 undergone OS; 5 undergone thoracoscopic repair). ${ }^{43}$ In fact, conversions for ventilation concerns were minimal in thoracoscopy; also, no postoperative outcome, including duration of postoperative mechanical ventilation, was related to thoracoscopic approach and intraoperative acidosis. ${ }^{42,43}$

Even though keeping an adequate arterial oxygenation might be vital to prevent neurological damage, ${ }^{42}$ it is still unknown whether hypercapnia and acidosis leading to prolonged postoperative low brain oxygenation ${ }^{20}$ have consequences on the long-term neurological development. ${ }^{43,44} \mathrm{~A}$ recent animal study from our group showed that neonatal $\mathrm{CO}_{2}$-pneumothorax has no significant outcome over neurodevelopment. ${ }^{45}$

Meanwhile several strategies can be found to minimize hypercapnia and acidosis during surgery. (1) Operating time is an important parameter to consider, minimizing lung collapse duration and $\mathrm{CO}_{2}$ exposure. (2) In thoracoscopy, the procedure might be completed with minimal $\mathrm{CO}_{2}$ insufflation: in the beginning of the surgery, insufflation is used to help reducing the herniated abdominal contents and is then decreased/interrupted. ${ }^{30,34}$ At our department, 4 to $6 \mathrm{~mm}$ $\mathrm{Hg}$ insufflation pressure has been applied until reduction of the herniated viscera and then diminished. The hypoplastic lungs provide wide working space, which makes $\mathrm{CDH}$ the ideal condition to perform thoracoscopy. ${ }^{30}$ (3) High frequency oscillatory ventilation (HFOV) is getting popular as it allowed excellent oxygenation and elimination of $\mathrm{CO}_{2}$ although it is still not established if it prevents acidosis balance after pneumothorax. ${ }^{46}$

\section{Right-sided CDH}

Right-sided CDH and intrathoracic liver present an additional challenge for the surgeon. The neonatal liver is extremely friable, and while positioning the liver in the abdomen. there is the risk of kinking of the hepatic veins and the inferior vena cava. Extreme caution must be taken while manipulating the liver into the abdomen while monitoring hemodynamic parameters. The division of the falciform ligament and rotation of the liver around the hepatic vein axis might be useful to avoid damaging the liver and the vessels. ${ }^{47}$

\section{Patients Requiring Extracorporeal Membrane Oxygenation}

In patients requiring extracorporeal membrane oxygenation (ECMO), the optimal timing to $\mathrm{CDH}$ repair is controversial due to the increased risk of complications including surgical bleeding (surgical site and intracranial bleeding) and mortality. Some authors report improved outcomes when surgery is performed off ECMO (significantly increased survival, lower rates of surgical bleeding, and decreased total duration of ECMO therapy compared with patients repaired on ECMO $){ }^{48}$ As so, patients who can be weaned from ECMO should undergo delayed repair off ECMO. In patients who would otherwise be unable to wean from ECMO, early surgery during ECMO should be performed, despite the associated risks. Surgery may improve respiratory function by restoring normal anatomy and even help coming off ECMO. ${ }^{49,50}$ Some authors reported the implementation of a specific anticoagulant protocol to reduce bleeding complications for patients operated during ECMO, using tranexamic acid, with good outcomes. ${ }^{51}$ Also, some details during surgery should be taken into account, namely the cautious use of electrocautery, limited blunt and sharp dissection, and use of prosthetic patch repair.

\section{Postoperative Complications}

\section{Mortality}

Although survival rate has improved in the last decades, the management of $\mathrm{CDH}$ remains a major challenge for both perinatology and neonatal surgery. ${ }^{52,53}$ The introduction of innovative techniques, including HFOV, inhaled nitric oxide, ECMO, gentle ventilation, and also the tremendous development in prenatal diagnosis contributed to improve the outcome of $\mathrm{CDH}$. Nowadays, several highly qualified centers report remarkable improvement in survival rates reaching $80 \%{ }^{54,55}$

The timing of surgery is not usually controversial: the neonate should be operated after clinical stabilization. However, when it comes to survival, some studies, including a Cochrane review of the literature, failed to demonstrate superiority of the delayed approach when compared with immediate surgery. ${ }^{56}$ The truth is there are no studies in the literature showing a negative effect for delayed surgery awaiting stabilization. ${ }^{47}$ While the question of the surgical timing remains unanswered, it is common sense that in the presence of an unstable neonate with $\mathrm{CDH}$ surgery should be postponed until cardiovascular stabilization is obtained.

Regarding the surgical approach, overall analysis showed no differences in mortality rate between OS and MIS, as proven by Landsdale et al in a meta-analysis in $2010 .{ }^{57}$ Several studies, after that, including meta-analysis, demonstrated higher mortality rate in the OS group $39,40,58,59$ though there are strong reasons to believe it was on account of selection bias: patients were selected for each of the techniques, and it is likely that the 
MIS group included less severe cases. The lower mortality in MIS group is most probably confounded by the fact that the cases were milder, which is supported by a retrospective study that compared thoracoscopy $(n=75)$ and OS $(n=43)$ among a group of cardiovascular stable neonates and showed a survival rate of $100 \%$ in both groups. ${ }^{44}$

The role of hospital volume in mortality remains unclear. In a large study with 2,203 infants, hospitals with a high volume $\mathrm{CDH}$ repairs had lower rates of in-hospital mortality. ${ }^{60}$ On the other hand, a study with 3,738 infants showed no differences in mortality between hospitals with lower and higher surgical volume. ${ }^{61}$

\section{Pneumothorax and Pleural Effusion}

Pleural complications are frequent after $\mathrm{CDH}$ repair. Postoperative pneumothorax occurs in nearly all patients. But clinically significant pneumothorax occurs in up to $30 \%$; pleural effusion requiring postoperative drainage occurs in up to $29 \%$ of patients with higher risk if a prosthetic patch was required; and chylothorax was reported in $\sim 6 \%$ of the cases, mainly associated with ECMO and use of prosthetic patch. Pneumothorax, pleural effusion, chylothorax, and need for aspiration were associated with higher rates of postoperative mortality. ${ }^{62,63}$ Historically, $\mathrm{CDH}$ was repaired by OS, and a chest tube was left in place, when perioperative management included aggressive hyperventilation, high peek inspiratory pressures, ventilation rates, and $\mathrm{O}_{2}$ concentrations. The introduction of gentle ventilation techniques and permissive hypercapnia as well as the event of MIS reduced the use of intraoperative prophylactic chest tubes. Some studies demonstrate no difference in the outcomes when not using a chest tube and argue that chest tube is associated with postoperative pain, pneumonia, atelectasis, prolonged ventilation duration, hospital stay, and risk of patch infection. ${ }^{27,64}$ Other authors claim that prophylactic chest tube decreases the need for postoperative interventions and morbidity associated with these procedures. ${ }^{63}$ It is the authors' conviction that, except for selected cases, no drain needs to be left intraoperatively. In the presence of a pneumothorax or pleural effusion causing cardiopulmonary distress, drainage should be performed promptly before instability occurs. ${ }^{4,62}$

\section{Recovery (Time on Ventilator, Time to First Feeding, and Length of Stay)}

Shorter and less aggressive mechanical ventilation limits ventilator-induced lung injury and thus improves prognosis. One of the major advantages of thoracoscopic repair over OS seems to be the decreased morbidity, namely for the quicker recovery. ${ }^{40}$ MIS was associated with significantly shorter ventilator time and ICU length of stay. In MIS, there was less time to tolerate enteral feeding as would be expected by reduced manipulation of intra-abdominal viscera leading to less ileus, less scarring and adhesions, and less pain. 33,39,44,65

\section{Recurrence}

The incidence of $\mathrm{CDH}$ recurrence ranges from 3 to $\sim 50 \%$, depending on the specific patient population and individual publication. ${ }^{66}$ Risk factors of recurrence are ECMO, defect size/prosthetic patch use and CDH repair by MIS. ${ }^{66,67}$ Most studies, including all meta-analysis conducted so far, reported significantly higher risk of recurrence after MIS $^{20,33,39,40,57,58,68}$ with a rate of 0 to $24 \%$ versus a rate of 0 to $11 \%$ in OS. $^{33}$ Costerus et al conducted a retrospective study, attempting to eliminate the case selection bias: they compared thoracoscopy $(n=75)$ and OS $(n=43)$ in a selected group of patients, all with left-sided $\mathrm{CDH}$, presenting criteria for thoracoscopic surgery according to $\mathrm{CDH}$ EURO consortium consensus, ${ }^{65}$ and the results matched the ones previously reported. It was partly explained by the learning curve (being a recent and technically demanding procedure), ${ }^{29,68}$ which was supported by the downward tendency in recurrence rate along the time (50\% recurrence rate in the previous years versus $25 \%$ in the following). ${ }^{59}$ However, this difference was not completely explained by the learning curve. Until now, no other predictive factors were found. ${ }^{22}$ The authors speculate that strict following of all the steps of OS might be vital to improve postoperative outcomes: (1) after the reduction of abdominal content to the peritoneal cavity, an important step was always to divide the pleura from the peritoneum along the edge of the diaphragm to encourage healing of the diaphragmatic defect; (2) either with separate or continuous suture, distance between stitches along the edge of the diaphragmatic defect should not exceed the same in OS (thoracoscopic suturing might be demanding, mainly if the working space is limited, which often leads the surgeon to perform a lower number of stiches); and (3) finally, horizontal mattress suturing technique with non-absorbable thread should be used (the type of suture might be determinant for recurrence). At our department, out of 13 children operated by thoracoscopy with this technique (3 using prosthesis), there was one recurrence (in 1 of those, we used prosthesis). ${ }^{30}$

Concerning the use of prosthetic patch, some authors strongly recommended converting to OS if a patch was needed $^{39}$ on the beliefs of higher recurrence rates. ${ }^{15,26,27,39}$ Once again, technical demandings might play an important role. The costophrenic angle is a difficult anatomical area to reach while performing intracorporeal suturing in very small neonates. ${ }^{20}$ An important trick one should consider while fastening the mesh to the diaphragmatic rims adjacent to the thoracic wall is to perform the suturing extracorporeally around the rib, introducing the thread in and out through the same subcutaneous tract, using interrupted mattress type sutures. $^{30}$

Keizer et al in 2010 concluded that recurrence rate was reduced after they had broaden their criteria to use a prosthetic patch by thoracoscopic repair. In primary repair, direct closure might result in undue tension on the suture line and was likely to reduce the natural dome shape of the diaphragm, increasing the intrathoracic space and decreasing the already reduced intra-abdominal space that still had to accommodate the reduced herniated viscera. The use of a larger prosthetic patch avoided the potential negative effects of direct closure and was likely to result in a lower chance of a recurrence. The same authors concluded that a recurrence 
either of MIS or OS repair could be repaired by thoracoscopy without compromising the outcomes (7 recurrences were repaired thoracoscopically with no recurrence after the second procedure). ${ }^{18}$

Careful attention to imaging prior to discharge, mainly after a MIS or a large defect repair, is advisable. ${ }^{59}$

\section{Bowel Obstruction}

Manipulation of intra-abdominal viscera leads to adhesions formation that might consequently cause bowel obstruction. Patients undergoing OS were more than five times more likely to undergo re-intervention for bowel obstruction secondary to adhesive disease, during their initial stay. ${ }^{59,69}$

We should be aware of other causes for postoperative bowel obstruction in $\mathrm{CDH}$ patients. In a retrospective study, Rescorla et al reported that $2.9 \%$ of patients with $\mathrm{CDH}$ not treated for malrotation presented with midgut volvulus. ${ }^{70}$

\section{Long-Term Morbidity}

The increasing survival rate changed the paradigm in the management of children with $\mathrm{CDH}$, directing the focus to improve morbidity. A significant number of $\mathrm{CDH}$ patients may live with complications (respiratory, nutritional, musculoskeletal, neurological, and gastrointestinal morbidities), resulting in poor quality of life. ${ }^{4,32,71}$ Long-term morbidity is mostly associated with perioperative complications, defect size, need for patch repair, liver-up, and the existence of major morbidities at discharge. ${ }^{32}$

Chronic respiratory disease is common in $\mathrm{CDH}$ patients, in some cases requiring oxygen at home for long periods of time. Diaphragmatic rigidity and thoracic deformities might play a minor role in chronic lung disease. ${ }^{4}$

Gastroesophageal reflux is frequent in these patients. Surgical repair changes the anatomy and might lead to a malformed or absent diaphragmatic sling. Also, malrotation may delay gastric emptying, and the abnormal thorax-abdomen balance of pressures through respiratory cycles facilitates retrograde passage of gastric contents to the esophagus. Anti-reflux surgery is required by several patients. ${ }^{4}$ The only randomized prospective study on the value of routine fundoplication did not recommend preventive antireflux surgery as a standard procedure. ${ }^{72}$

Due to long periods of marginal brain oxygenation in neonatal period (especially those in ECMO) neurodevelopmental deficits can occur in $\mathrm{CDH}$ survivors. Neurosensorial deafness can also occur, which is generally associated with prolonged antibiotic treatments. ${ }^{4}$

Finally, concerning cosmesis, the effects of OS in neonatal period, namely in a condition where the need for wide visualization often requires a large incision, are documented well: unaesthetic scars and musculoskeletal deformities (if a thoracotomy was performed). ${ }^{73}$ Again, thoracoscopic repair has the well-known advantages of elimination of musculoskeletal deformities and leaving a discreet scar, which courses with significantly decreased long-term morbidity.

The management of these conditions starts by preventing perioperative complications. Providing a close follow-up and permanent support is mandatory especially in those who present risk factors for long-term morbidity.

\section{Conclusion}

The best approach of $\mathrm{CDH}$ is yet to be found, and it goes far beyond the management of perioperative complications. Meanwhile, surgical morbidity in $\mathrm{CDH}$ patients is considerable. MIS, namely thoracoscopy, reduced the incidence of some perioperative complications, but randomized controlled studies are required to inform further practice.

\section{Conflict of Interest}

None.

\section{References}

1 McGivern MR, Best KE, Rankin J, et al. Epidemiology of congenital diaphragmatic hernia in Europe: a register-based study. Arch Dis Child Fetal Neonatal Ed 2015;100(02):F137-F144

2 Gomes Ferreira C, Kuhn P, Lacreuse I, et al. Congenital diaphragmatic hernia: an evaluation of risk factors for failure of thoracoscopic primary repair in neonates. J Pediatr Surg 2013;48(03):488-495

3 Reiss I, Schaible T, van den Hout L, et al; CDH EURO Consortium. Standardized postnatal management of infants with congenital diaphragmatic hernia in Europe: the CDH EURO Consortium consensus. Neonatology 2010;98(04):354-364

4 Tovar JA. Congenital diaphragmatic hernia. Orphanet J Rare Dis 2012;7(01):1

5 Greer JJ, Babiuk RP, Thebaud B. Etiology of congenital diaphragmatic hernia: the retinoid hypothesis. Pediatr Res 2003;53(05): 726-730

6 Puri P, Wester T. Historical aspects of congenital diaphragmatic hernia. Pediatr Surg Int 1997;12:95-100

7 Shanbhogue LK, Tam PK, Ninan G, Lloyd DA. Preoperative stabilisation in congenital diaphragmatic hernia. Arch Dis Child 1990; 65(10 Spec No):1043-1044

8 Silen ML, Canvasser DA, Kurkchubasche AG, Andrus CH, Naunheim KS. Video-assisted thoracic surgical repair of a foramen of Bochdalek hernia. Ann Thorac Surg 1995;60(02):448-450

9 van der Zee DC, Bax NM. Laparoscopic repair of congenital diaphragmatic hernia in a 6-month-old child. Surg Endosc 1995;9(09):1001-1003

10 Becmeur F, Jamali RR, Moog R, et al. Thoracoscopic treatment for delayed presentation of congenital diaphragmatic hernia in the infant. A report of three cases. Surg Endosc 2001;15(10):1163-1166

11 Arca MJ, Barnhart DC, Lelli JL Jr, et al. Early experience with minimally invasive repair of congenital diaphragmatic hernias: results and lessons learned. J Pediatr Surg 2003;38(11):1563-1568

12 Yang EY, Allmendinger N, Johnson SM, Chen C, Wilson JM, Fishman SJ. Neonatal thoracoscopic repair of congenital diaphragmatic hernia: selection criteria for successful outcome. J Pediatr Surg 2005;40(09):1369-1375

13 Kalfa N, Allal H, Raux O, et al. Multicentric assessment of the safety of neonatal videosurgery. Surg Endosc 2007;21(02):303-308

14 Gomes Ferreira C, Reinberg O, Becmeur F, et al. Neonatal minimally invasive surgery for congenital diaphragmatic hernias: a multicenter study using thoracoscopy or laparoscopy. Surg Endosc 2009;23(07):1650-1659

15 Cho SD, Krishnaswami S, Mckee JC, Zallen G, Silen ML, Bliss DW. Analysis of 29 consecutive thoracoscopic repairs of congenital diaphragmatic hernia in neonates compared to historical controls. J Pediatr Surg 2009;44(01):80-86

16 Gourlay DM, Cassidy LD, Sato TT, Lal DR, Arca MJ. Beyond feasibility: a comparison of newborns undergoing thoracoscopic 
and open repair of congenital diaphragmatic hernias. J Pediatr Surg 2009;44(09):1702-1707

17 Shah SR, Wishnew J, Barsness K, et al. Minimally invasive congenital diaphragmatic hernia repair: a 7-year review of one institution's experience. Surg Endosc 2009;23(06):1265-1271

18 Keijzer R, van de Ven C, Vlot J, et al. Thoracoscopic repair in congenital diaphragmatic hernia: patching is safe and reduces the recurrence rate. J Pediatr Surg 2010;45(05):953-957

19 Lao OB, Crouthamel MR, Goldin AB, Sawin RS, Waldhausen JHT, Kim SS. Thoracoscopic repair of congenital diaphragmatic hernia in infancy. J Laparoendosc Adv Surg Tech A 2010;20(03):271-276

20 McHoney M, Giacomello L, Nah SA, et al. Thoracoscopic repair of congenital diaphragmatic hernia: intraoperative ventilation and recurrence. J Pediatr Surg 2010;45(02):355-359

21 Okazaki T, Nishimura K, Takahashi T, et al. Indications for thoracoscopic repair of congenital diaphragmatic hernia in neonates. Pediatr Surg Int 2011;27(01):35-38

22 Gander JW, Fisher JC, Gross ER, et al. Early recurrence of congenital diaphragmatic hernia is higher after thoracoscopic than open repair: a single institutional study. J Pediatr Surg 2011;46 (07):1303-1308

23 Tsao K, Lally PA, Lally KP; Congenital Diaphragmatic Hernia Study Group. Minimally invasive repair of congenital diaphragmatic hernia. J Pediatr Surg 2011;46(06):1158-1164

24 Gupta RK, Parelkar SV, Oak SN, et al. Early experience with thoracoscopic repair of congenital diaphragmatic hernias in pediatric age group: results and lessons learned. Pediatr Surg Int 2011;27(06):563-566

25 Liem NT, Nhat LQ Tuan TM, Dung A, Ung NQ Dien TM. Thoracoscopic repair for congenital diaphragmatic hernia: experience with 139 cases. J Laparoendosc Adv Surg Tech A 2011;21(03):267-270

26 Szavay PO, Obermayr F, Maas C, Luenig H, Blumenstock G, Fuchs J. Perioperative outcome of patients with congenital diaphragmatic hernia undergoing open versus minimally invasive surgery. J Laparoendosc Adv Surg Tech A 2012;22(03):285-289

27 Tsao K, Lally KP. Surgical management of the newborn with congenital diaphragmatic hernia. Fetal Diagn Ther 2011;29(01): 46-54

$28 \mathrm{Nam}$ SH, Cho MJ, Kim DY, Kim SC. Shifting from laparotomy to thoracoscopic repair of congenital diaphragmatic hernia in neonates: early experience. World J Surg 2013;37(11):2711-2716

29 Jancelewicz T, Langer JC, Chiang M, Bonnard A, Zamakhshary M, Chiu PP. Thoracoscopic repair of neonatal congenital diaphragmatic hernia (CDH): outcomes after a systematic quality improvement process. J Pediatr Surg 2013;48(02):321-325

30 Barroso C, Correia-Pinto J. Thoracoscopic repair of congenital diaphragmatic hernia, review of the results. Minerva Pediatr 2017. Doi: 10.23736/S0026-4946.17.05110-6

31 McHoney M. Congenital diaphragmatic hernia. Early Hum Dev 2014;90(12):941-946

32 Takayasu H, Masumoto K, Jimbo T, et al. Analysis of risk factors of long-term complications in congenital diaphragmatic hernia: A single institution's experience. Asian J Surg 2017;40(01):1-5

33 Vijfhuize S, Deden AC, Costerus SA, Sloots CEJ, Wijnen RMH. Minimal access surgery for repair of congenital diaphragmatic hernia: is it advantageous?-an open review Eur J Pediatr Surg 2012;22(05):364-373

34 Fishman JR, Blackburn SC, Jones NJ, et al. Does thoracoscopic congenital diaphragmatic hernia repair cause a significant intraoperative acidosis when compared to an open abdominal approach? J Pediatr Surg 2011;46(03):458-461

35 Bliss D, Matar M, Krishnaswami S. Should intraoperative hypercapnea or hypercarbia raise concern in neonates undergoing thoracoscopic repair of diaphragmatic hernia of Bochdalek? J Laparoendosc Adv Surg Tech A 2009;19(Suppl 1):S55-S58

36 Maxwell D, Baird R, Puligandla P. Abdominal wall closure in neonates after congenital diaphragmatic hernia repair. J Pediatr Surg 2013;48(05):930-934
37 Moss RL, Chen CM, Harrison MR. Prosthetic patch durability in congenital diaphragmatic hernia: a long-term follow-up study. J Pediatr Surg 2001;36(01):152-154

38 Nagata K, Usui N, Terui K, et al. Risk factors for the recurrence of the congenital diaphragmatic hernia-report from the long-term follow-up study of Japanese CDH study group. Eur J Pediatr Surg 2015;25(01):9-14

39 Chan E, Wayne C, Nasr A. Minimally invasive versus open repair of Bochdalek hernia: a meta-analysis. J Pediatr Surg 2014;49(05): 694-699

40 Zhu Y, Wu Y, Pu Q, Ma L, Liao H, Liu L. Minimally invasive surgery for congenital diaphragmatic hernia: a meta-analysis. Hernia 2016;20(02):297-302

41 Hiradfar M, Shojaeian R, Gharavi Fard M. Two-stage endoscopic repair of congenital diaphragmatic hernia. BMJ Case Rep 2016; 2016;. Doi: 10.1136/bcr-2016-214591

42 Zani A, Lamas-Pinheiro R, Paraboschi I, et al. Intraoperative acidosis and hypercapnia during thoracoscopic repair of congenital diaphragmatic hernia and esophageal atresia/tracheoesophageal fistula. Pediatr Anesth 2017;27(08):841-848

43 Bishay M, Giacomello L, Retrosi G, et al. Hypercapnia and acidosis during open and thoracoscopic repair of congenital diaphragmatic hernia and esophageal atresia: results of a pilot randomized controlled trial. Ann Surg 2013;258(06):895-900

44 Costerus S, Zahn K, van de Ven K, Vlot J, Wessel L, Wijnen R. Thoracoscopic versus open repair of $\mathrm{CDH}$ in cardiovascular stable neonates. Surg Endosc 2016;30(07):2818-2824

45 Miranda A, Roque S, Serre-Miranda C, Pêgo JM, Correia-Pinto J. Inflammatory response and long-term behavioral assessment after neonatal CO2-pneumothorax: study in a rodent model. J Pediatr Surg 2017. Doi: 10.1016/j.jpedsurg.2017.08.016

46 Mortellaro VE, Fike FB, Adibe OO, et al. The use of high-frequency oscillating ventilation to facilitate stability during neonatal thoracoscopic operations. J Laparoendosc Adv Surg Tech A 2011;21 (09):877-879

47 Zani A, Zani-Ruttenstock E, Pierro A. Advances in the surgical approach to congenital diaphragmatic hernia. Semin Fetal Neonatal Med 2014;19(06):364-369

48 Partridge EA, Peranteau WH, Rintoul NE, et al. Timing of repair of congenital diaphragmatic hernia in patients supported by extracorporeal membrane oxygenation (ECMO). J Pediatr Surg 2015;50 (02):260-262

49 McHoney M, Hammond P. Role of ECMO in congenital diaphragmatic hernia. Arch Dis Child Fetal Neonatal Ed 2017. Doi: 10.1136/ archdischild-2016-311707

50 Robertson JO, Criss CN, Hsieh LB, et al. Comparison of early versus delayed strategies for repair of congenital diaphragmatic hernia on extracorporeal membrane oxygenation. J Pediatr Surg 2017. Doi: $10.1016 /$ j.jpedsurg.2017.10.056

51 Keijzer R, Wilschut DE, Houmes RJ, et al. Congenital diaphragmatic hernia: to repair on or off extracorporeal membrane oxygenation? J Pediatr Surg 2012;47(04):631-636

52 Downard CD, Jaksic T, Garza JJ, et al. Analysis of an improved survival rate for congenital diaphragmatic hernia. J Pediatr Surg 2003;38(05):729-732

53 Doyle NM, Lally KP. The CDH Study Group and advances in the clinical care of the patient with congenital diaphragmatic hernia. Semin Perinatol 2004;28(03):174-184

54 Antonoff MB, Hustead VA, Groth SS, Schmeling DJ. Protocolized management of infants with congenital diaphragmatic hernia: effect on survival. J Pediatr Surg 2011;46(01):39-46

55 Okuyama H, Kitano Y, Saito M, et al. The Japanese experience with prenatally diagnosed congenital diaphragmatic hernia based on a multi-institutional review. Pediatr Surg Int 2011;27(04):373-378

56 Moyer V, Moya F, Tibboel R, Losty P, Nagaya M, Lally KP. Late versus early surgical correction for congenital diaphragmatic hernia in newborn infants. Cochrane Database Syst Rev 2002;(03): CD001695 
57 Lansdale N, Alam S, Losty PD, Jesudason EC. Neonatal endosurgical congenital diaphragmatic hernia repair: a systematic review and meta-analysis. Ann Surg 2010;252(01):20-26

58 Terui K, Nagata K, Ito M, et al. Surgical approaches for neonatal congenital diaphragmatic hernia: a systematic review and metaanalysis. Pediatr Surg Int 2015;31(10):891-897

59 Putnam LR, Tsao K, Lally KP, et al; Congenital Diaphragmatic Hernia Study Group and the Pediatric Surgery Research Collaborative. Minimally invasive vs open congenital diaphragmatic hernia repair: is there a superior approach? J Am Coll Surg 2017; 224(04):416-422

60 Bucher BT, Guth RM, Saito JM, Najaf T, Warner BW. Impact of hospital volume on in-hospital mortality of infants undergoing repair of congenital diaphragmatic hernia. Ann Surg 2010;252 (04):635-642

61 Kane JM, Harbert J, Hohmann S, et al. Case volume and outcomes of congenital diaphragmatic hernia surgery in academic medical centers. Am J Perinatol 2015;32(09):845-852

62 Casaccia G, Crescenzi F, Palamides S, Catalano OA, Bagolan P. Pleural effusion requiring drainage in congenital diaphragmatic hernia: incidence, aetiology and treatment. Pediatr Surg Int 2006;22(07): 585-588

63 Schlager A, Arps K, Siddharthan R, Clifton MS. Tube thoracostomy at the time of congenital diaphragmatic hernia repair: reassessing the risks and benefits. J Laparoendosc Adv Surg Tech A 2017;27 (03):311-177

64 Ponsky TA, Rothenberg SS, Tsao K, Ostlie DJ, St Peter SD, Holcomb GW III. Thoracoscopy in children: is a chest tube necessary? J Laparoendosc Adv Surg Tech A 2009;19(01, Suppl 1):S23-S25

65 Snoek KG, Reiss IK, Greenough A, et al; CDH EURO Consortium. Standardized postnatal management of infants with congenital diaphragmatic hernia in Europe: the CDH EURO Consortium Consensus - 2015 update. Neonatology 2016;110(01):66-74

66 Putnam LR, Gupta V, Tsao K, et al. Source of support: Center for Clinical and Translational Sciences Training Award, University of NU. J Pediatr Surg 2017. Doi: 10.1016/j.jpedsurg.2017.03.011

67 Janssen S, Heiwegen K, van Rooij IA, et al. Factors related to long-term surgical morbidity in congenital diaphragmatic hernia survivors. J Pediatr Surg 2017. Doi: 10.1016/j.jpedsurg.2017.05.032

68 Lishuang M, Yandong W, Shuli L, et al. A comparison of clinical outcomes between endoscopic and open surgery to repair neonatal diaphragmatic hernia. J Minim Access Surg 2017;13(03): 182-187

69 Davenport M, Rothenberg SS, Crabbe DCG, Wulkan ML. The great debate: open or thoracoscopic repair for oesophageal atresia or diaphragmatic hernia. J Pediatr Surg 2015;50(02): 240-246

70 Rescorla FJ, Shedd FJ, Grosfeld JL, Vane DW, West KW. Anomalies of intestinal rotation in childhood: analysis of 447 cases. Surgery 1990;108(04):710-715

71 Peetsold MG, Heij HA, Kneepkens CM, Nagelkerke AF, Huisman J, Gemke RJ. The long-term follow-up of patients with a congenital diaphragmatic hernia: a broad spectrum of morbidity. Pediatr Surg Int 2009;25(01):1-17

72 Maier S, Zahn K, Wessel LM, Schaible T, Brade J, Reinshagen K. Preventive antireflux surgery in neonates with congenital diaphragmatic hernia: a single-blinded prospective study. J Pediatr Surg 2011;46(08):1510-1515

73 Wei S, Saran N, Emil S. Musculoskeletal deformities following neonatal thoracotomy: long-term follow-up of an esophageal atresia cohort. J Pediatr Surg 2017;52(12):1898-1903 